\title{
Immunoelectron Microscopic Localization of Cell Surface Antigens on Rat Hepatocytes Detected with Monoclonal Antibodies (HAM2 and HAM4)
}

\author{
Kazuhito Yamaguchi, Yoshihisa Fujikura*, Hiromichi Kuniki*, Kazuo Itoh*, Katsutoshi \\ Tamakoshi $^{* *}$, and Tetsuo Fukumoto* \\ Institute of Laboratory Animals and *Department of Anatomy, Yamaguchi University School of Medicine, \\ Ube, Yamaguchi 755, and ${ }^{* *} 2$ nd Internal Medicine, Hamamatsu University School of Medicine, Hamamatsu, \\ Shizuoka 431-31, Japan
}

Key words: rat/monoclonal antibody/hepatocyte/immunoelectron microscopy/cell polarity

\begin{abstract}
$A B S T R A C T$. The localization of surface antigens and the binding activity of two monoclonal antibodies, HAM2 and HAM4, which recognize the rat major histocompatibility complex (MHC) antigen class I and the rat hepato-renal antigen respectively, on dissociated (free) hepatocytes was examined by light (LM) and electron microscopy (EM), and by radioimmunoassay (RIA). Fixed hepatocytes, fixed before dissociation, and fresh hepatocytes, dissociated by collagenase, were treated by direct staining with HAM2- or HAM4-immunogold complexes (HAM2-gold and HAM4-gold). Some of the directly stained hepatocytes were further mixed with antimouse IgG-gold complex (IgG-gold) to supplement the direct staining.

The polarity of the sinusoidal and contiguous faces and the bile canaliculus, i.e. the in situ morphology, was well preserved in the fixed hepatocytes, while the fresh cells had lost the polarity and were round. On the fixed hepatocytes HAM2-gold particles were distributed predominantly on the sinusoidal face, while HAM4-gold particles were localized on both the bile canalicular and sinusoidal faces. No different antigen distribution on the fresh cells was detected with the two antibodies. Supplementation by IgG-gold was noticeable in most cases. The extent of binding activity in both the immunogold and RIA experiments was lower in the fixed cells than in fresh cells.

These results suggest that HAM2 and HAM4 are useful monoclonal antibodies for detecting the localization of the MHC class I antigen and the hepato-renal antigen on the hepatocytes, respectively.
\end{abstract}

An important feature of the hepatocyte is that it has polarity of structure and function. It has three faces: sinusoidal, contiguous, and bile canalicular. The sinusoidal face has a large microvillar surface area, specialized for the exchange of metabolites with the blood. The bile canalicular face has a small microvillar surface area where bile secretion takes place. The contiguous face is a smooth surface where the cells interact with neighboring cells. The existence of biochemical component which might correlate with the different functions occurring at the three faces was suggested by the isolation of liver plasma-membrane subfractions which have different densities, and by the respective morphologic features and specific enzymes $(4,5,24)$. Some other kinds of cell membrane molecules-insulin receptor (3), the receptor for asialoglyco-protein (11), and the secretory component for IgA (17)-have been studied biochemically, and the localization of each molecule on the hepatocyte surface can be examined morphologically to some extent $(16,19)$. However, the details concerning the localization of these molecules on the three faces of the hepatocyte have not yet been studied. The monoclonal antibody technique developed by Kohler and Milstein (12) has accelerated the characterization of cell membrane molecules, primarily on lymphocytes $(13$, 23).

Then, using the immunoperoxidase or immunogold techniques, details concerning the localization of membrane molecules detected with monoclonal antibodies have begun to be examined by electron microscopy. Such combinations of electron microscopical localization of cell surface molecules by the monoclonal antibody technique would contribute greatly to clarifying the molecular functions of the various cell surfaces. Such studies might be especially useful for cells which have highly polarized cell surfaces with different functions, such as intestinal epithelial cells or hepatocytes.

We have reported 5 different monoclonal antibodies to rat hepatocyte membrane antigens (HAM1, HAM2, HAM3, HAM4, and HAM5) $(7,8,21)$, and have re- 
ported the biochemical natures of these antigens (9). HAM1 and HAM3 antibodies are hepatocyte-specific and do not react with other cells such as lymphocytes. HAM2 recognizes rat major histo-compatibility antigen (MHC) Class I $(8,9)$. HAM4 recognizes a rat hepatorenal membrane antigen (21). HAM5 reacts with both fetal and adult hepatocytes (7).

The localization of each antigen recognized by these monoclonal antibodies was examined with immunohistochemical staining and observed by light microscopy: HAM2 appeared on the sinusoidal face, while HAM4 stained mainly the bile canaliculus of hepatocytes (21). HAM1, HAM3, and HAM5 stained rather weakly on light microscopical immunohistochemistry, and it was difficult to determine the localization of the antigens detected by these monoclonal antibodies.

This paper describes further details of the distribution of HAM2 and HAM4 antigens, analyzed by electron microscopy (EM) with the immunogold technique.

\section{MATERIALS AND METHODS}

Animals. Young male adults (150-200 gm body weight) of DA rat from the stock maintained at the Institute of Laboratory Animals in our medical school were used in this study.

Preparation of isolated cells. Two kinds of free cells, fixed and fresh hepatocytes, from rat liver were obtained by the following procedures.

1) Fixed hepatocytes (hepatocytes fixed before dissociation). In order to preserve the in situ morphology or polarity of hepatocytes showing three different compartments (sinusoidal and contiguous faces and bile canaliculus), animals were perfused via the thoracic aorta with approximately $30 \mathrm{ml}$ of $8 \%$ paraformaldehyde $/ 0.01 \%$ glutaraldehyde in $0.1 \mathrm{M}$ phosphate buffer ( $\mathrm{pH}$ 7.4) (22) for $10 \mathrm{~min}$, followed by $10 \mathrm{ml}$ of $0.1 \mathrm{M}$ glycine in phosphate buffered saline (PBS) in order to wash out and block the aldehyde groups. After the perfusion, the livers were sliced with a razor blade to about 1 $\mathrm{mm}$ thickness, and the slices were further immersed in $0.1 \mathrm{M}$ glycine for $30 \mathrm{~min}$ at $4^{\circ} \mathrm{C}$. To obtain isolated cells, the slices were dissociated by digestion with $50 \mathrm{ml}$ of collagenase solution [Hank's balanced salt solution containing $2.5 \mathrm{mg}$ of collagenase (purchased from Wako Pure Chemical Industries Ltd., Japan)] for $30 \mathrm{~min}$ at $37^{\circ} \mathrm{C}$ with gentle stirring. The isolated cells were rinsed with $0.1 \%$ BSA-PBS [PBS containing $0.1 \%$ bovine serum albumin (BSA)].

2) Fresh hepatocytes. Fresh hepatocytes were prepared by the method described by Berry and Friend (2). Animals were perfused for $45 \mathrm{~min}$ via the portal vein with $300 \mathrm{ml}$ of collagenase solution $(5 \mu \mathrm{g} / \mathrm{ml})$ warmed to $37^{\circ} \mathrm{C}$. After the perfusion, the livers were dissociated with a spatula in Hank's solution, and the isolated cells were rinsed with BSA-PBS.

Some of the isolated fresh hepatocytes were fixed for 10 min with the same fixative as used in perfusion fixation and then rinsed with BSA-PBS.
Antibodies. Two monoclonal antibodies (HAM2 and HAM4) and sheep F(ab') ${ }_{2}$ anti-mouse IgG were used. HAM2 recognizes the rat MHC Class I antigen (8), the molecular weight of which is approximately $43,000(9)$. HAM4 is a monoclonal antibody to wheatgerm-lectin binding membrane glycoprotein prepared from rat hepatocytes (21). HAM4 reacts with the bile canalicular face of hepatocytes as well as the epithelia of the bile duct and the renal proximal tubules of rat (21).

Sheep $\mathrm{F}\left(\mathrm{ab}^{\prime}\right)_{2}$ anti-mouse $\mathrm{IgG}(\mathrm{H} \& \mathrm{~L}$ specific) was purchased from Cappel Laboratories Inc., USA.

Immunogold complex formation (HAM2-gold, HAM4gold, and IgG-gold). Colloidal gold solutions of $25 \mathrm{~nm}$ and $41 \mathrm{~nm}$ sizes were made in accordance with Frens' method (6), and immunogold complexes were formed by the method described by Roth (20). IgG fractions of HAM2 and HAM4 monoclonal antibodies were purified from mouse ascites by the method of Mason and Williams (15). The IgG fractions were dialyzed in $20 \mathrm{mM}$ borate buffer ( $\mathrm{pH} 8.2)$.

To make immunogold complexes, gold solutions were adjusted to $\mathrm{pH} 8.2$ with $0.2 \mathrm{M} \mathrm{K}_{2} \mathrm{CO}_{3}$ just before conjugation. Four hundred micrograms of IgG from HAM2 or HAM4 ascites were added to $10 \mathrm{ml}$ of the $25-\mathrm{nm}$ gold solution, and 200 $\mu \mathrm{g}$ of sheep $\mathrm{F}(\mathrm{ab})_{2}$ anti-mouse IgG were added to $10 \mathrm{ml}$ of the 41-nm gold solution. The solutions were gently mixed by pipetting for $2 \mathrm{~min}$. After mixing, BSA (in distilled water adjusted to $\mathrm{pH} 8.2$ with $\mathrm{NaOH}$ and microfiltered) was added to yield a final concentration of $1 \%$. After centrifugation, the sedimented immunoglobulin-gold complexes were resuspended in $20 \mathrm{mM}$ Tris buffered saline ( $\mathrm{pH} 8.2$ ) containing $1 \%$ BSA. The centrifugation was repeated twice, and the complexes were finally resuspended in $1.5 \mathrm{ml}$ of Tris buffered saline containing $1 \% \mathrm{BSA}$ and $0.02 \% \mathrm{NaN}_{3}$ and stored at $4{ }^{\circ} \mathrm{C}$. The immunoglobulin concentration was determined by a microversion of the method described by Lowry et al. (14) with BSA as the standard, using a Hitachi spectrophotometer at $750 \mathrm{rm}$ wave length.

Immunogold staining. Two kinds of immunogold staining were carried out.

1) Direct staining $(D)$. Cell suspensions (containing $1 \times$ $10^{5}$ cells $/ 100 \mu \mathrm{l}$ ) were mixed with $25 \mu \mathrm{l}$ of HAM2-gold or HAM4-gold and the incubation was continued for 3 to $12 \mathrm{~h}$ at $4^{\circ} \mathrm{C}$. The cells were rinsed with $1 \%$ BSA-PBS 3 times.

2) Supplemented staining $(S)$. A portion of the cell suspensions treated by direct staining was further mixed with anti-mouse IgG-gold for 6 to $12 \mathrm{~h}$ at $4^{\circ} \mathrm{C}$ to supplement the direct staining (1).

3) Tissue slices. Some fixed tissue slices digested by collagenase were also treated or supplemented by the same staining procedure and prepared for microscopic examinations.

4) Control groups Three control groups were prepared: one group was treated with 25 -nm gold solution, a second with IgG-gold without primary antibody treatment, and the third was untreated. 
Preparation for $L M$ and $E M$. After the direct or supplemented staining, cells were fixed with $2 \%$ glutaraldehyde in $0.1 \mathrm{M}$ phosphate buffer ( $\mathrm{pH} \mathrm{7.4)}$ for $10 \mathrm{~min}$. For LM, cells were settled on glass slides (see below) without osmification, dehydrated with a graded alcohol series, and mounted in a neutral mounting medium.

For transmission EM (TEM), cell pellets were postfixed with $2 \%$ osmic acid for $2 \mathrm{~h}$, dehydrated with a graded acetone series, and embedded in Epon 812. Sections appearing violet due to the reflection of light (approximately $190 \mathrm{~nm}$ ) were examined with a JEOL 200CX transmission electron microscope at $160 \mathrm{kV}$ without staining for TEM. To compare the distribution of immunogold complexes among the three different faces, the gold particles were counted on the TEM photographs using a Zeiss dissection microscope.

For scanning EM (SEM), osmificated cells in suspensions were settled on glass slides coated with poly-l-lysine $(1 \mathrm{mg} / \mathrm{ml})$ in a humidified chamber at $4^{\circ} \mathrm{C}$ overnight. Cells were then dehydrated with a graded acetone series, coated with a 10 to 15 $\mathrm{nm}$ thickness of platinum, and examined with a JEOL T-300 scanning electron microscope at $15 \mathrm{kV}$.

Radioimmunoassay $(R I A)$. To compare the degree of membrane antigen expression detected by these monoclonal antibodies on the fixed and fresh hepatocytes, the binding activities of HAM2 and HAM4 monoclonal antibodies with the cells were examined by an indirect radioactive binding assay following the method of Fukumoto et al. (8). Briefly, $50 \mu \mathrm{l}$ of tissue culture supernatant, either diluted with PBS or undiluted, was incubated with an equal volume of freshly prepared or fixed hepatocytes. After incubation for $1 \mathrm{~h}$ on ice, the cells were washed three times by centrifugation at $200 \times \mathrm{g}$ for 5 min, and then $50 \mu \mathrm{l}$ of ${ }^{125} \mathrm{I}$-sheep $\mathrm{F}\left(\mathrm{ab}^{\prime}\right)_{2}$ anti-mouse IgG $(0.2$ $\mu \mathrm{g} / \mathrm{ml} ; 12.5 \mu \mathrm{Ci} / \mu \mathrm{g}$ in PBS-0.5\% BSA) was added in a second, similar incubation. The cells were finally washed three times and cell-bound radioactivity was counted in a Hitachi automatic well counter.

\section{RESULTS}

Hepatocytes, fixed and fresh, treated by direct (D) or supplemented (S) staining with immunogold complexes (HAM2-gold, HAM4-gold, and IgG-gold) were examined by LM, TEM, and SEM. The binding activity of HAM2 or HAM4 to the membrane of each cell type was also examined by RIA.

I. LM; General observations. When free hepatocytes were treated by direct staining with HAM2-gold (HAM2-D) or HAM4-gold (HAM4-D), the cells in all cases were colored pale pink by the binding of the 25 nm gold particles. In the cases of HAM2-S and HAM4$\mathrm{S}$, the color of the cells was changed from pale pink to red or violet by the binding of the 41-nm gold particles. This shows that the direct staining had been supplemented by anti-mouse IgG-gold. The staining of fresh cells was greater than that of fixed cells. In fixed cells the staining by HAM4-gold was slightly heavier than that by HAM2-gold.

Fixed hepatocytes. The fixed hepatocytes appeared polyhedral. When the cells were treated with HAM2-D or $-\mathrm{S}$, the cell surface was stained nonuniformly by the gold particles (Fig. 1).

The gold labeling by HAM4-D or HAM4-S was more characteristic than by HAM2-D or $-S$. The cells had irregular lines and speckes on their surfaces (Fig. 2). These irregular lines were distinctly observed on the tissue slices treated by HAM4-S (Fig. 3). The lines on a given cell continued to the adjacent cells and formed a network as a whole. They were located at a certain area of the hepatocytes and at the border of the adjacent cells in a given hepatic cord. This localization might correspond with the area of the bile canaliculus of the liver. The sinusoidal face was also stained by HAM4-gold, and was seen as a speck on the isolated cells (Fig. 2, arrow).

These results with the fixed hepatocytes show that HAM2-gold is distributed around the cells, whereas HAM4-gold is localized at the bile canaliculus and sinusoidal face of the cells.

Fresh hepatocytes. Most of the fresh hepatocytes were round, although a few protuberances were observed on the surfaces of some cells. When cells were treated by HAM2-D or -S or by HAM4-D or -S, the cell surface became dark in all cases, and the protuberances were stained darker than the rest of the cell surface (Figs. 4 and 5). This patchy staining suggests the possibility that cap formation occurred on living cells during staining. To examine whether cap formation causes patchy staining or not, fresh cells were briefly fixed (fresh-fixed hepatocytes) and treated as well. The morphology of these fresh-fixed hepatocytes was similar to that of the fresh cells. No patchy staining was observed, although the cells were stained. The stainability by HAM2-gold or HAM4-gold was slightly higher in the fresh cells, but no other significant differences in staining were found.

Control groups. No color changes in the cells of any control group were detected when either fixed or fresh hepatocytes were treated.

II. EM; General observations. Free hepatocytes, fixed or fresh, observed by SEM and TEM are illustrated in Figs. 6 to 9. On the fixed cells (Figs. 6 and 7), the characteristic in situ morphology or polarity of the hepatocytes, which are polyhedral with three faces (sinusoidal, contiguous, and bile canalicular), was well observed after the collagenase digestion. Cell organelles also retained their morphology. On the fresh hepatocytes, however, the in situ morphology disappeared, and they transformed into round cells with numerous microvilli on the surfaces (Figs. 8 and 9). Protuberances, which usually had no microvilli, were observed 

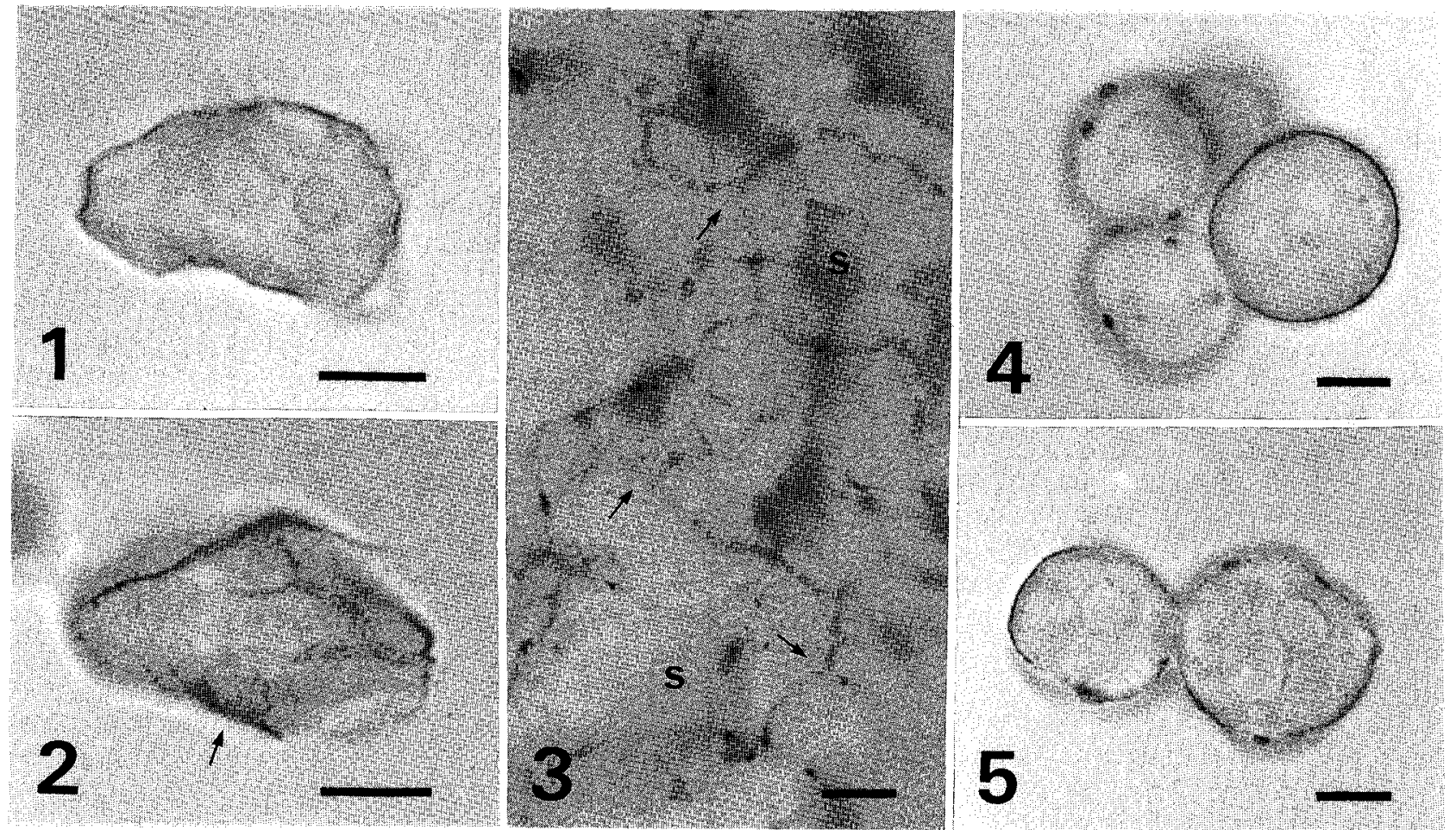

Figs. 1-5. Light micrographs of dissociated (free) hepatocytes and a liver tissue slice. Bars show $10 \mu \mathrm{m}$.

Fig. 1. A fixed hepatocyte treated by HAM2-S. The cell is polyhedral and is irregularly stained with gold particles.

Fig. 2. A fixed hepatocyte treated by HAM4-S. A dark branching line suggesting the bile canaliculus and a dark speck (arrow) are seen on the cell.

Fig. 3. A liver tissue slice treated by HAM4-S. Continuous dark lines on hepatic cords and their branchings (arrows) are well observed. s: Sinusoidal face.

Figs. 4. and 5. Fresh hepatocytes treated by HAM2-S (Fig. 4) and HAM4-S (Fig. 5). The cells appear round. Protuberances and patchy distributions are found on their surfaces.

on a considerable number of the cells (Fig. 8). Organelles in the fresh cells retained their own morphology, although vacuoles appeared in the cytoplasm (Figs. 14 and 15). The fresh-fixed hepatocytes did not retain the in situ morphology as well as did the fresh cells, and their shapes were slightly distorted. No marked cytoplasmic changes were observed except for the formation of vacuoles.

Fixed hepatocytes by TEM. Each border among the three compartments was precisely distinguished as follows: The area where microvilli appeared (for example, Fig. 11A, arrowhead between $\mathrm{c}$ and s) was decided to be the border between the contiguous and sinusoidal faces, because the contiguous face, in general, has no microvilli, and the dark area (for example, Fig. 13A, the two arrowheads existing between $c$ and $b$ ) showing the junctional complex between hepatocytes was decided on as the border between the contiguous face and bile canaliculus (Figs. 10-13). Gold particles were observed on the surfaces of cells treated by HAM2-D (Fig. 10). The distribution of the particles tended to be denser on the microvilli of the sinusoidal face than on the contiguous and bile canalicular faces. When cells were treated by HAM4-D, the distribution of gold particles was predominantly localized on the bile canalicular and sinusoidal faces of the cells (Fig. 11). The particles tended to accumulate much more on the bile canalicular surface.

On the cells treated by HAM2-S (Fig. 12) and HAM4$S$ (Fig. 13), a significant increase in the number of gold particles was observed only in the case of HAM4-S (Fig. 13); in the other cases no increase was found. At higher magnification of the areas, the increases of each sized gold particle (25 and $41 \mathrm{~nm}$ ) were distinguishable (Fig. 13B).

The numbers of gold particles localized on the sinusoidal, contiguous, and bile canalicular faces on the fixed hepatocytes are shown in Table I. The results shown were analyzed statistically using Student's $t$ test. With HAM2, no difference in the number of particles was seen among the three faces, although on the sinusoidal face it was slightly greater. With HAM4, in contrast, the number of particles on the bile canaliculus was about twice and four times that of the sinusoidal 

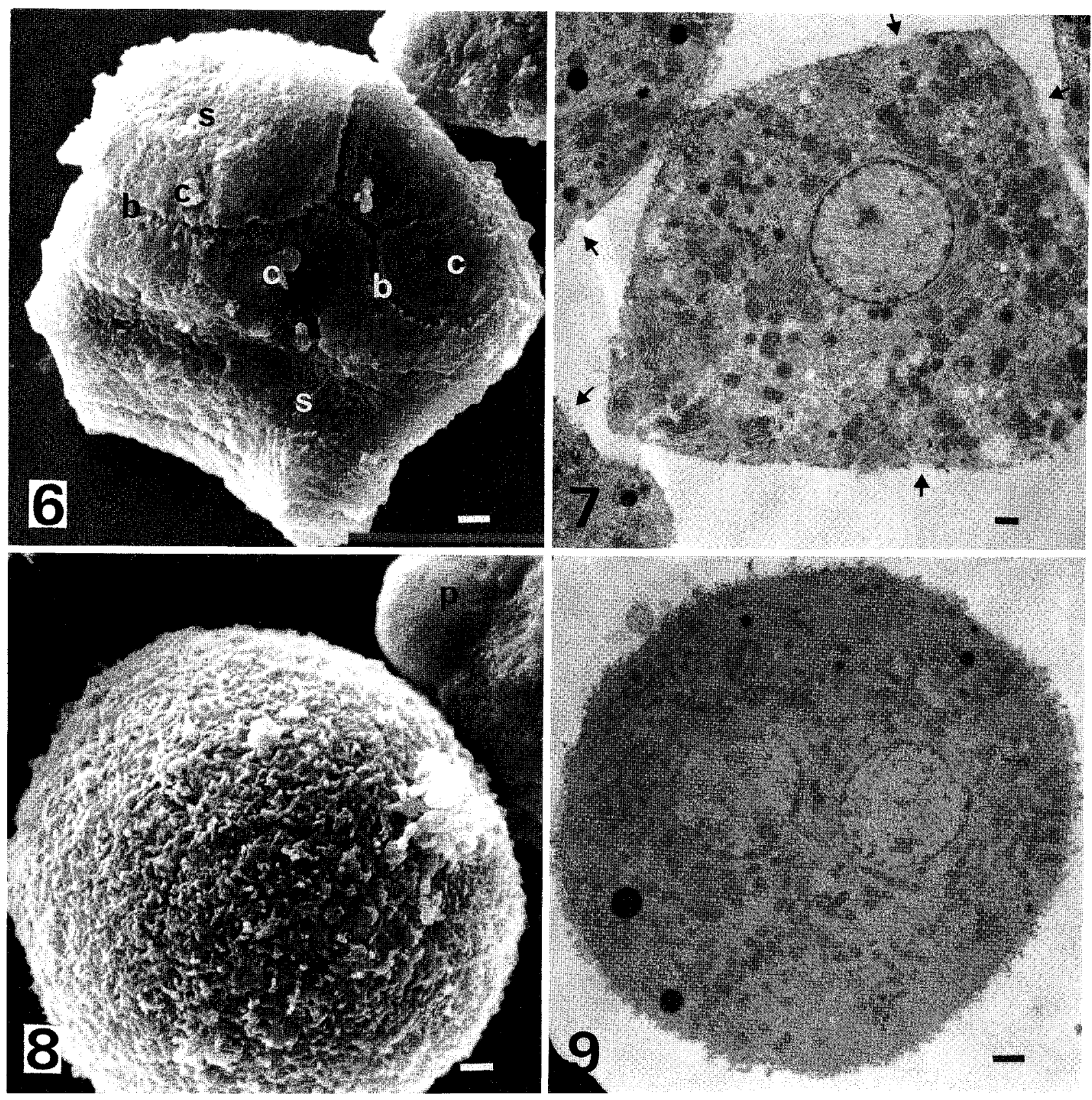

Figs. 6-9. Scanning (Figs. 6 and 8) and transmission (Figs. 7 and 9) electron micrographs of free hepatocytes. The bars in all electron micrographs of this paper indicate $1 \mu \mathrm{m}$.

Figs. 6. and 7. Fixed hepatocytes treated by HAM2-D. The cells appear polyhedral and preserve their polarity or three faces: sinusoidal (s) and contiguous (c) faces and bile canaliculus (b). The morphology of the cells is retained well. The arrows in Fig. 7 show the bile canaliculi of the hepatocytes.

Figs. 8. and 9. Fresh hepatocytes treated by HAM2-S. The cells are round and have numerous microvilli on the surfaces. The cell polarity of hepatocytes in situ has disappeared. A protuberance (p) of a cell is seen at the upper right in Fig. 8.

and contiguous faces, respectively. Furthermore, the supplementation by anti-mouse IgG-gold was distinctive only on the bile canaliculus with HAM4-S. The results in Table I seem to support the observations by

\section{LM and TEM.}

Fresh hepatocytes by TEM. When fresh hepatocytes were treated by HAM2-D or -S or by HAM4-D or -S, a large number of gold particles were distributed on the 


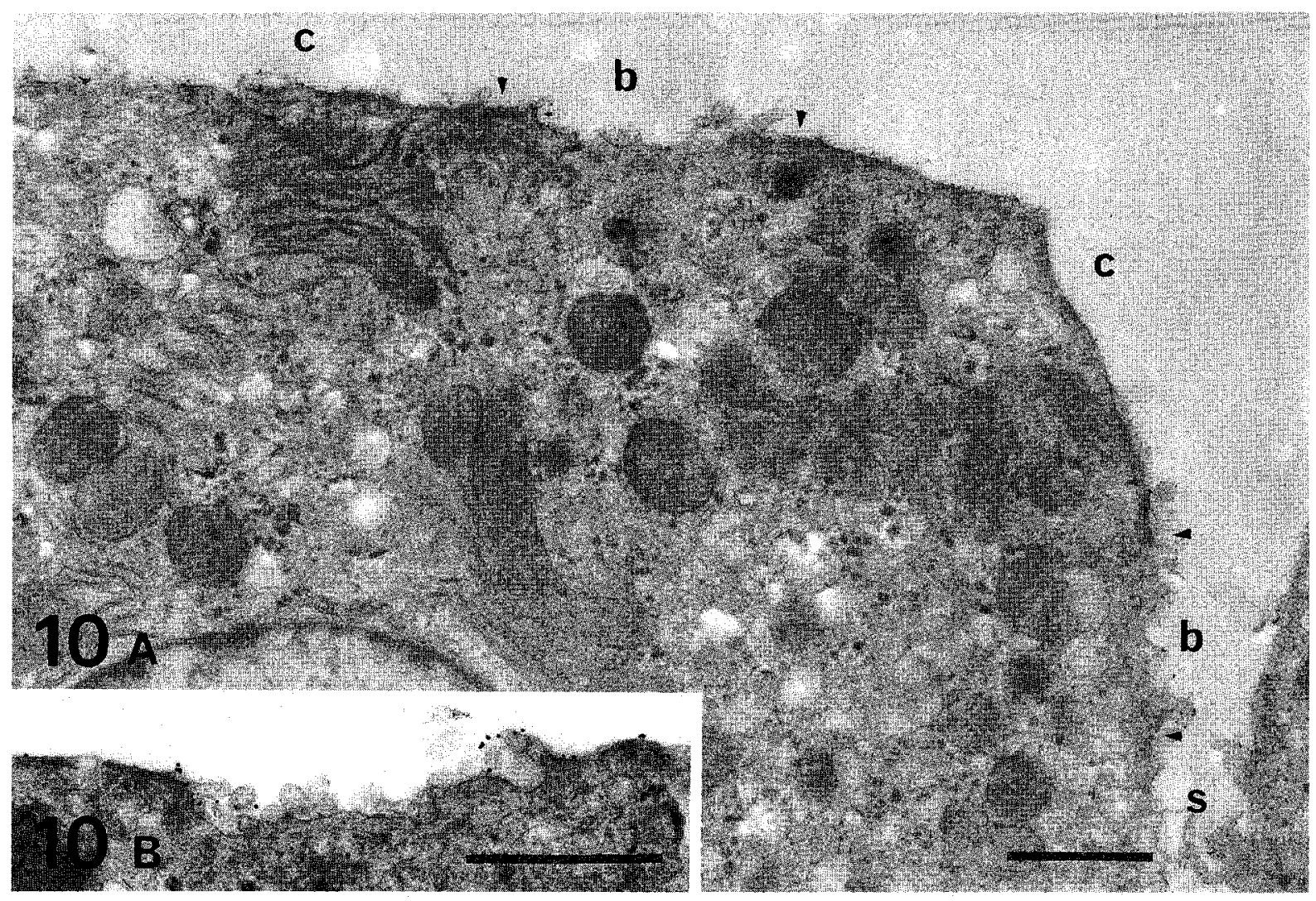

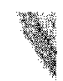

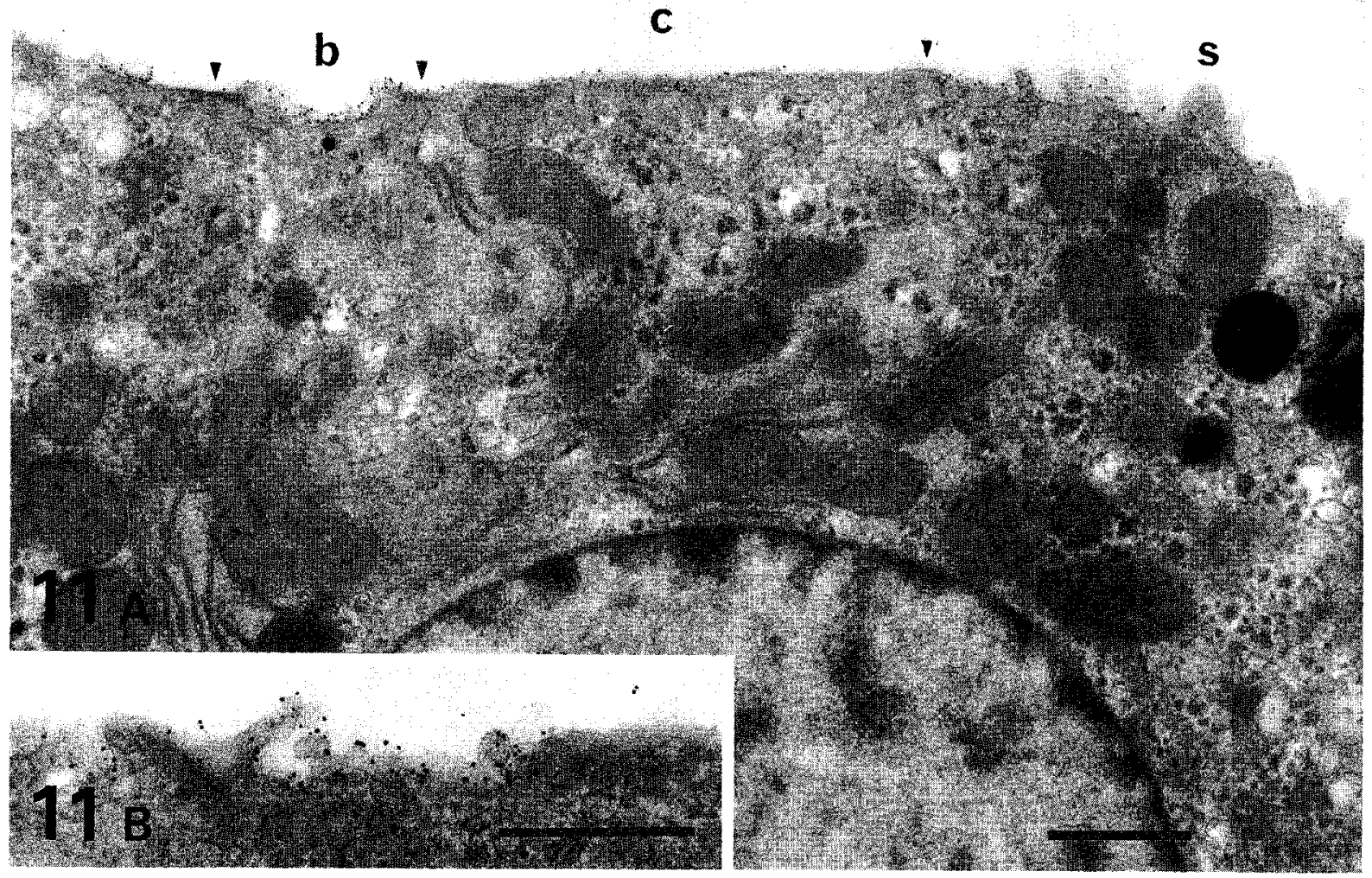



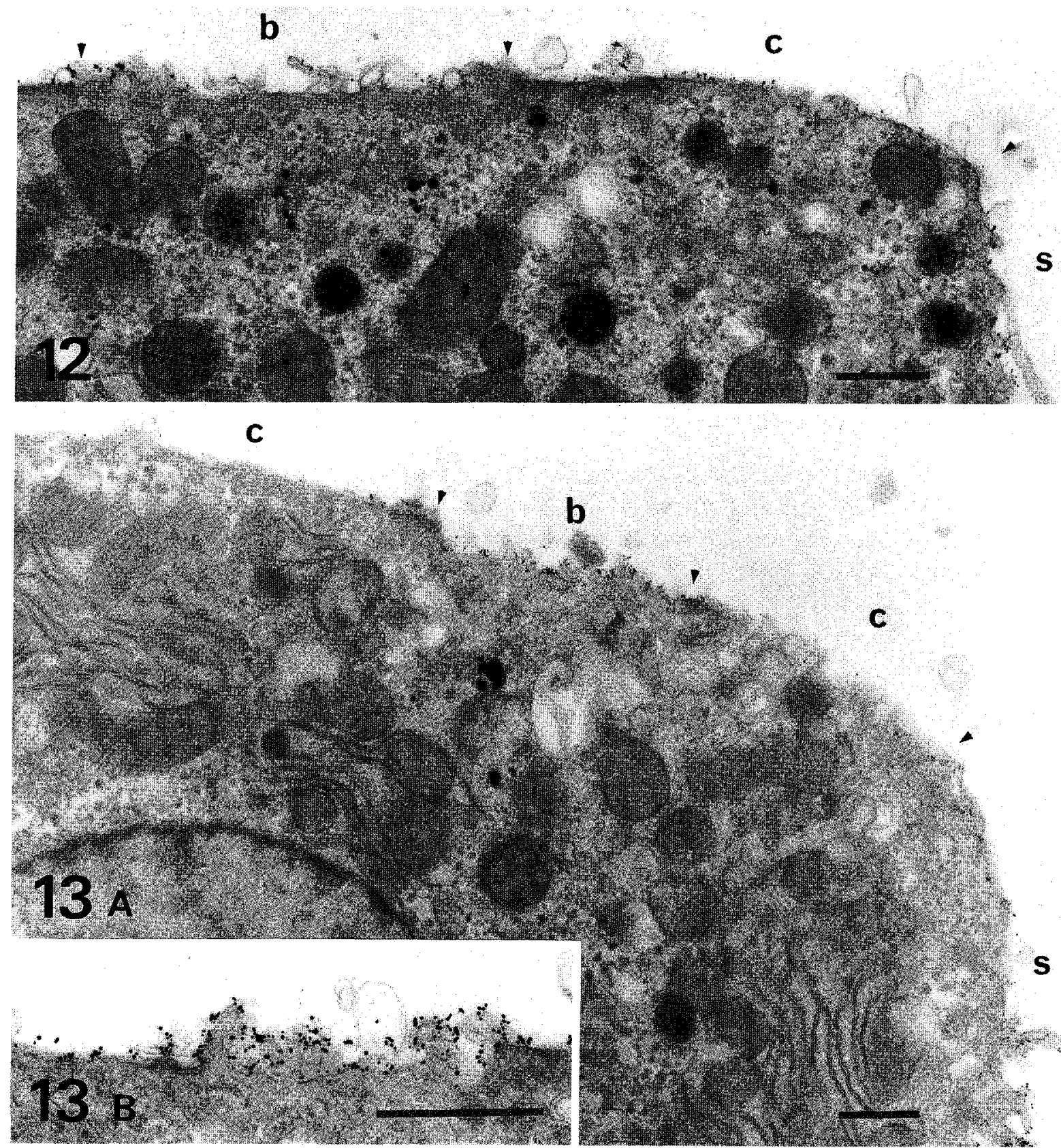

\section{S}


Table I. Number of GOLd Particles on the sinusoidal, bile CANALICUlar, AND CONTIGUOUS FACES OF PRE-FIXED HEPATOCYTES.

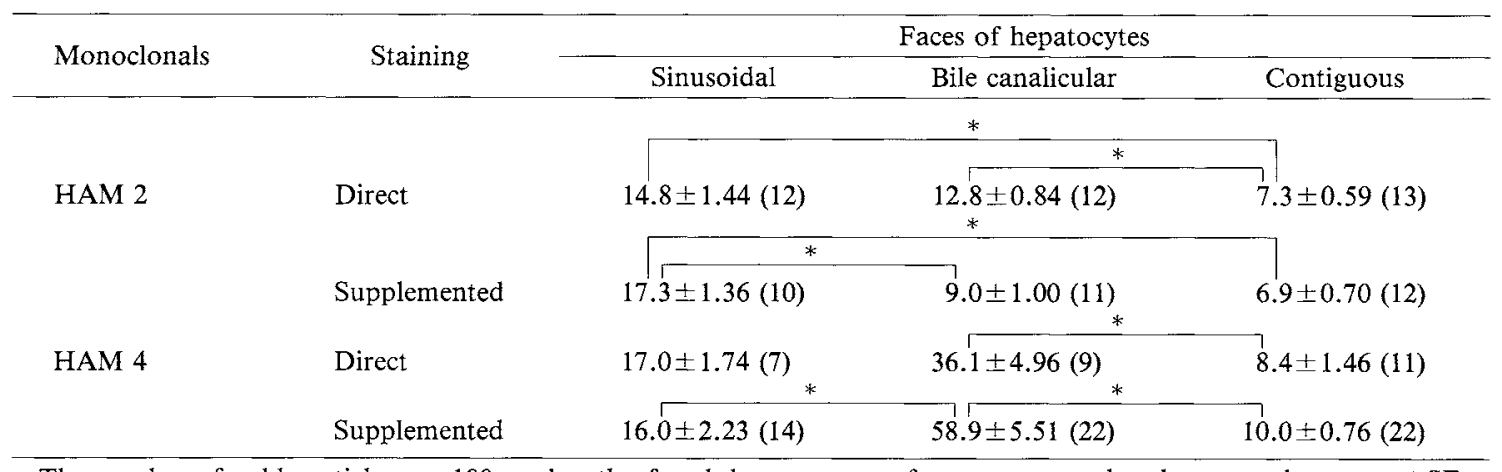

The number of gold particles per $100 \mu \mathrm{m}$ length of each hepatocyte surface was counted and expressed as mean \pm SE.

The numbers in parentheses indicate the number of cells.

* Statistically different from each other at $\mathrm{p}<0.001$.

cells (Figs. 14 to 16 ), and the supplementation was found with both HAM2-S and HAM4-S. However, no characteristic localizations were detected in any case except for patchy accumulations of gold particles in the cases of both HAM2-gold and HAM4-gold (Fig. 14). Gold particles tended to localize at the basal part of the microvilli or at the intermicrovillar surfaces of the cells (Figs. 15 and 16). In contrast, gold particles were evenly distributed on the surfaces of the fresh-fixed hepatocytes, especially on the microvilli (Fig. 17). No patchy accumulation was found in this case. This shows that cap formation was blocked by the fixation. In general, the stainability of the fresh hepatocytes by immunogold complexes was greater than that of the fixed hepatocytes. This finding accorded with the data of the RIA (Table II).

SEM. Although fixed and fresh hepatocytes treated with immunogold complexes were examined by SEM, unlike the TEM no clear difference in the distributions of gold particles was found in any case.

Control groups. No gold particles suggesting specific binding to cells were detected in any control group (Fig. 18).

III. RIA; The result of the indirect radioactive binding assay on fixed and fresh hepatocytes treated with HAM2 or HAM4 is shown in Table II. The data in Table II show that both HAM2 and HAM4 had bound strongly to the fixed or fresh cells, while the binding of each monoclonal antibody to the fixed cells was lower than that to the fresh cells. The data also show that the binding of HAM4 to the fixed cells was significantly greater than that of HAM2. These results support the observations by LM and TEM.

\section{DISCUSSION}

The main purpose of this study was to reveal differences in the binding sites for two monoclonal antibodies, HAM2 and HAM4, on the sinusoidal, contiguous, and bile canalicular faces of hepatocytes. As shown, the perfusion fixation in situ is essential to preserve the in situ morphology or the polarity of hepatocytes (Figs. 6 and 7), although the antigenic activity is reduced by the fixation (Table II).

We observed that on the fixed hepatocytes, HAM2gold stained well the sinusoidal face of the cells, while HAM4-gold was predominantly localized on the bile canaliculus but was also significantly observed on the sinusoidal face. This HAM4 distribution is in contrasts with the findings from light microscopical analysis reported by us previously (21): That is HAM4 distribution was rather restricted to the bile canalicular face. The predominant localization of HAM2 antigens on the sinusoidal faces may be important for hepatocytic communication with endothelial cells and Kupffer cells. Alternatively, several humoral factors derived from the blood may affect the expression of MHC Class I antigen on this side of hepatocytes, as only this face may be often exposed to the blood-borne humoral factors. The localization of HAM4 antigens on not only the bile

Fig. 14. Fresh hepatocytes treated by HAM2-S. One cell has a protuberance, and patchy accumulations of gold particles are seen on the surface.

Figs. 15. and 16. Fresh hepatocytes treated by HAM2-D (Fig. 15) and HAM4-D (Fig. 16). Many gold particles are distributed along the surface of both cells, but not on the microvilli.

Fig. 17. A fresh-fixed hepatocyte treated by HAM4-D. Many gold particles are localized primarily on the microvilli, as compared with the fresh cells (Figs. 15 and 16).

Fig. 18. A fixed hepatocyte treated with IgG-gold (control). Three gold particles on the bile canaliculus (b) and the contiguous (c) and sinusoidal (s) faces are visible in this figure. Arrowheads show the border of each face. 

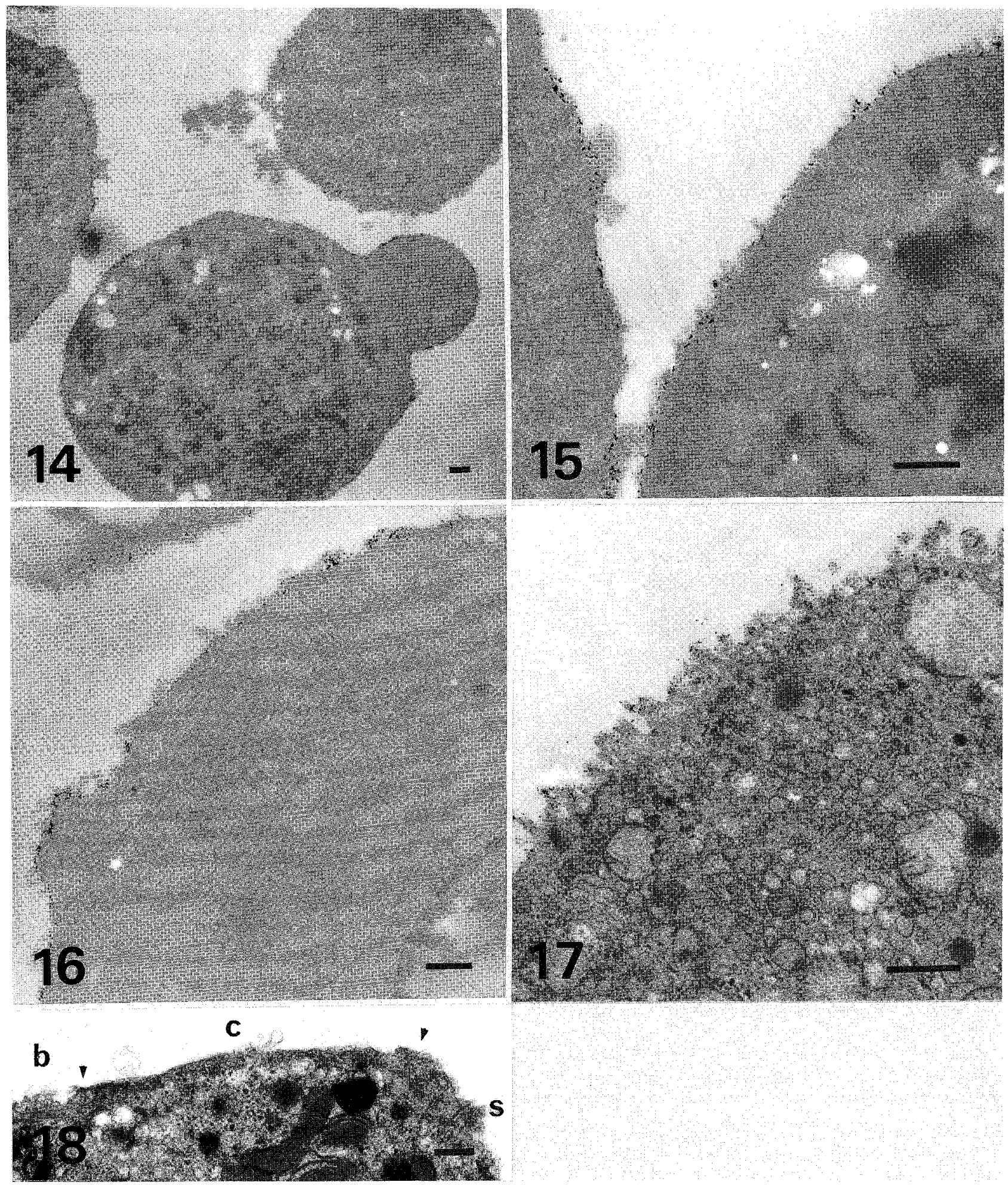

canaliculus but also the sinusoidal face, where the microvilli usually develop, suggests that HAM4 antigen may be related to transport of some molecules in the hepatocytes.

In this study, we used the immunogold technique to detect membrane antigens by direct staining (HAM2- 
Table II. BINDING OF MONOCLONAL ANTIBODIES (HAM 2 AND HAM 4) TO THE MEMBRANE OF RAT HEPATOCYTES.

\begin{tabular}{llcc}
\hline Hepatocytes & \multicolumn{1}{c}{ HAM 2 } & HAM 4 & Control \\
\hline Pre-fixed & $17,535 \pm 2,105$ & $36,308 \pm 3,216$ & $7,301 \pm 773$ \\
Fresh & $45,872 \pm 327$ & $54,239 \pm 1,174$ & $3,191 \pm 168$
\end{tabular}

Radioactivity bound to hepatocytes (cpm) was expressed as mean \pm SE. Immunoglobulin secreted by mouse myeloma cells (P3-X) was used as a control.

gold or HAM4-gold, $25 \mathrm{~nm}$ ) and to supplement the direct staining using a secondary antibody bound with gold particles (IgG-gold, $41 \mathrm{~nm}$ ). The usefulness of the immunogold technique for the detection of surface immunoglobulin on human B lymphocytes by LM and TEM was first described by Geoghegan et al. (10). They suggested that this technique is useful in quantitating antibody binding sites on the cell surface by TEM and can reduce damage to cell morphology due to the peroxidase reaction with peroxidase-conjugated antibody. The technique's usefulness was confirmed in this study, in which the antibody binding sites on the hepatocytes were analyzed quantitatively (Table I) while no morphological damage was found in the cells. The supplementation by indirect staining was also noticeable in that the color of treated cells became deep on the LM. On the TEM, a significant increase in the number of gold particles was visible on the bile canaliculus with use of HAM4-S (Fig. 13). In contrast, on the sinusoidal and contiguous faces, the number of gold particles was not increased by either HAM2-S (Fig. 12) or HAM4-S, though the two kinds of particles were distinguishable there. The differences in binding by the supplemented staining among the 3 faces as compared with labeling by direct staining might be due to the stability of the newly formed doubly bound immunogold complexes (25-nm gold plus 41-nm gold) on the cell surfaces. In the case of the bile canaliculus, the number of the first antibody bound is great, and the double complexes may be stable, enabling many to be observed. As the number of the first antibody bound is small in the cases of the sinusoidal and contiguous faces, the double complexes may become unstable, and may possibly detach from the membrane.

An interesting observation is that the binding sites of immunogold on the microvilli were different between fixed and fresh hepatocytes. This finding suggests that the antibody binding sites of the membrane might move on living hepatocytes during the immunogold staining. This also suggests the possibility of cap formation on hepatocytes, similar to that observed on lymphocytes. However, active pinocytosis was not observed in this study. This fact might be a result of a reduction in pinocytic activity due to the processing being carried out at $4^{\circ} \mathrm{C}$ throughout the experiment. As shown in Table II, the binding of HAM2 and HAM4 to the free hepatocytes were clearly seen, and the fixative appeared to decrease the binding of both monoclonal antibodies. This effect was greater with HAM2 than with HAM4. This result suggests that the HAM2 target molecules might be less stable under the fixation processing than the HAM4 target antigen. In contrast, the binding of HAM4 to the fixed cells was greater than that of HAM2. Similar findings were obtained by both LM and TEM. These findings are thought due to the HAM4 binding sites, such as on the bile canaliculus and sinusoidal face, being well preserved on the fixed cells; the HAM4 binding sites would thus be retained more often than those of HAM2. Another possibility is that the number of HAM4 antigens is much greater than that of HAM2.

\section{REFERENCES}

1. Bendayan, M. and Duhr, M-A. (1986). Modification of the protein A-gold immunocytochemical technique for the enhancement of its efficiency. J. Histochem. Cytochem., 34: 569-575.

2. Berry, M.N. and Friend, D.S. (1969). High yield preparation of isolated rat liver parenchymal cells. A biochemical and fine structural study. J. Cell. Biol., 43: 506-520.

3. Cuatrecasas, P. (1972). Affinity chromatography and purification of the insulin receptor of liver cell membranes. Proc. Natl. Acad. Sci. USA, 69: 1277-1281.

4. Evans, W.H. (1970). Fractionation of liver plasma membrane prepared by zonal centrifugation. Biochem. J., 116: 833-842.

5. Evans, W.H. and GuRd, J.W. (1971). Biosynthesis of liver membranes. Incorporation of ${ }^{3} \mathrm{H}$-leucine into proteins and of ${ }^{14} \mathrm{C}$-glucosamine into proteins and lipids of liver microsomal and plasma-membrane fractions. Biochem. J., 125: 615-624.

6. FRENS, G. (1973). Controlled nucleation for the regulation of the particle size in monodisperse gold suspensions. Nature, 241: 20-22.

7. Fujikura, Y., Kuniki, H., and Fukumoto, T. (1985). Monoclonal antibodies against fetal rat liver cells. Bull. Yamaguchi Med. Sch., 32: 1-4.

8. Fukumoto, T., Kimura, H., Naito, M., Miyamoto, M., Yamashita, A., and SugiYama, H. (1984). Monoclonal antibodies to rat liver cell membrane glycoproteins. Mol. Immunol., 21: 285-291.

9. Fukumoto, T., Tamakoshi, K., Ohta, H., Yamashta, A., and MAEDA, K. (1986). Purification and characterization of MHC Class I antigen from rat liver with monoclonal antibody. Int. J. Biochem., 18: 971-977.

10. Groghegan, W.D., Scillian, J.J., and Ackerman, G.A. (1978). The detection of human B lymphocytes by both light and electron microscopy utilizing colloidal gold labeled antiimmunoglobulin. Immunol. Comm., 7: 1-12.

11. Kawasaki, T. and Ashwell, G. (1976). Chemical and physical properties of a hepatic membrane protein that specifically binds asialoglycoproteins. J. Biol. Chem., 251: 1296-1302.

12. Kohler, G. and MLstein, C. (1975). Continuous culture of fused cells secreting antibody of predefined specificity. Nature, 256: $495-497$.

13. Kung, P.C., Goldstein, G., Reinherz, E.L., and Schlossman, S.F. (1979). Monoclonal antibodies defining distinct human $T$ 
cell surface antigens. Science, 206: 347-349.

14. Lowry, O.H., Rosebrough, N.J., FarR, A., and Randall, R.J. (1951). Protein measurement with the Folin phenol reagent. J. Biol. Chem., 193: 265-275.

15. Mason, D.W. and Willtams, A.F. (1980). The kinetics of antibody binding to membrane antigens in solution and at the cell surface. Biochem. J., 187: 1-20.

16. Matsuura, S., Eto, S., Kato, K., and Tashiro, Y. (1984). Ferritin immunoelectron microscopic localization of 5'-nucleotidase on rat liver cell surface. $J$. Cell. Biol., 99: 166-173.

17. Mostov, K.E. and Friedlander, M., and Blobel, G. (1984). The receptor for transepithelial transport of IgA and IgM contains multiple immunoglobulin-like domains. Nature, 308: $37-$ 43.

18. Nicholson, B.J., Hunkapiller, M.W., Grim, L.B., HoOd, L.E., and Revel, J.P. (1981). Rat liver gap junction protein: Properties and partial sequence. Proc. Natl. Acad. Sci. USA, 78: 7594-7598.

19. PARR, E.L. (1979). Diversity of expression of $\mathrm{H}-2$ antigens on mouse liver cells demonstrated by immunoferritin labeling.
Transplantation, 27: 45-48.

20. Roтн, J. (1983). The colloidal gold marker system for light and electron microscopic cytochemistry. In Techniques in Immunocytochemistry (G.R. Bullock and P. Petrusz, eds.). Academic Press, London. P.217-284.

21. Tamakoshi, K., Fukumoto, T., Kanai, K., and Yamashita, A. (1985). A monoclonal antibody to a rat hepato-renal membrane antigen. Clin. exp. Immunol., 60: 373-380.

22. VAN EWIJK, W., VAN SOEST, P.L., Verkerk, A., and JONGKIND, J.F. (1984). Loss of antibody binding to prefixed cells: fixation parameters for immunocytochemistry. Histochem. J., 16: 179-193.

23. Williams, A.F., Galfre, G., and Milstein, C. (1977). Analysis of cell surfaces by xenogenic myeloma hybrid antibodies; differentiation antigens of rat lymphocytes. Cell, 12: 663-673.

24. Wisher, M.H. and Evans, W.H. (1975). Functional polarity of the rat hepatocyte surface membrane. Isolation and characterization of plasma-membrane subfractions from the bloodsinusoidal, bile-canalicular and contiguous surfaces of the hepatocyte. Biochem. J., 146: 375-388.

(Received for publication, March 1, 1991

and in revised form, May 11, 1991) 